Tracer Simulation Study of

Potential Solute Movement

in Port Royal Sound,

South Carolina

GEOLOGICAL SURVEY WATER-SUPPLV PAPER 1586-J

Prepared in cooperation with the South Carolina Water Resources Commission. 


\section{Tracer Simulation Study of Potential Solute Movement in Port Royal Sound, South Carolina}

By F. A. KILPATRICK and T. R. CUMMINGS

HY D R L OGY OF TIDAL STREAM S

GEOLOGICAL SURVEY WATER-SUPPLY PAPER 1586-J

Prepared in cooperation with the South Carolina Water Resources Commission

Effects of introducing a solute into an estuary

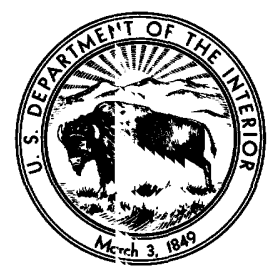




\section{UNITED STATES DEPARTMENT OF THE INTERIO"}

ROGERS C. B. MORTON, Secretary

GEOLOGICAL SURVEY

V. E. McKelvey, Director

Library of Congress catalog-card No. 72-600165

For sale by the Superintendent of Documents, U.S. Government Printing Office Washington, D.C. 20402 - Price 55 cents

Stock Number 2401-2196 


\section{CONTENTS}

Page

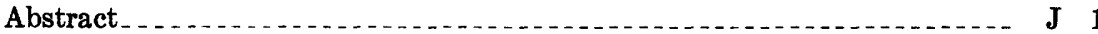

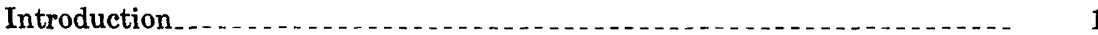

Acknowledgments . .

Method of study 3

Study area $\ldots \ldots \ldots$

Type of estuary

Tidal hydraulies....... 7

Tracer test. ........ 9

Tracer injection. 9

Sampling

Laboratory analysis . .

Data analysis and interpretation . . . 14

Low-slack-water isoconcentration maps.

High-slack-water isoconcentration maps. .

Ultimate pattern of concentration with continuous injection........ 22

Discussion and conclusions .

Application of results

Conservative concentrations. 26

Effect of injection at other locations...

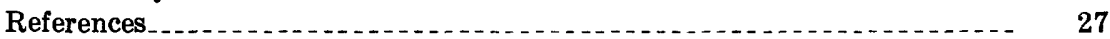

\section{ILLUSTRATIONS}

FIgURE 1. Map of Port Royal Sound and vicinity

2. Illustration of superposition principle.

3. Hydrologic map of Port Royal Sound

4. Map showing maximum variations in specific conductance, di solved oxygen, and $\mathrm{pH}$ in Port Royal Sound.

5. Recorded stage and estimated discharge hydrographs for Colletcn River showing tracer injection schedule and initial movement. -

6. Photographs of dye injection on the Colleton River. .......

7. Precipitation, and wind direction and strength, for Port Royal Sound; estimated discharge hydrograph for Colleton River showing injection and sampling schedule for the first 2 weels of the tracer test.

8. Photograph of one of several automatic floating samplers $\ldots \ldots$ 
FIGURES 9-15. Selected low-slack-tide isoconcentration maps showin\} movement of tracer cloud:

9. Maximum seaward movement on the initial ebb tiłe

10. Tracer remaining in upstream reaches because of dispersion effect.

11. Location and magnitude of dye cloud after injection had ceased.

12. First significant flushing into the Broad River . . . . . . 18

13. Time and distribution of dye at first arrival with $A$ tlantic Ocean

14. Recession of peak up Colleton River.

15. Final observation of dye cloud

16. Isoconcentration map of tracer cloud at high slack tide........ 23

17. Graphs of concentration curves for selected locations along main tracer plume.

18. Map of ultimate concentrations for a nonconservative solute

\section{TABLE}

TABLE 1. Computation of ultimate concentrations for selected locations in Port Royal Sound.

\section{SYMBOLS AND DEFINITION OF TERMS}

Concentration. Weight of tracer or solute per volume of water; expressed in micrograms per liter, $\mu \mathrm{g} / \mathrm{l}$.

Ebb tide. Refers to discharge or current in a seaward or downstream direction.

Flood tide. Refers to discharge or current in a shoreward or upstrəam direction.

High and low slack waters. The time, or brief period, between flood and ebb tides in which no net current, or significant movement, takes place.

High and low tide. Refers to tidal stage rather than current or discharge; high or low tide usually preceed the times of high or low slack waters. High high tide refers to the higher of the two high tides that occur in a tidal day.

Conservative solutes. Substances which are not decomposed, alter?d chemically, and removed physically as a result of natural processes.

Tidal cycle. One ebb and one flood tide.

Tidal day. Two tidal cycles or normally 24.8 hours in duration.

Tidal excursion. Distance a tidal volume of water moves from ebb to flood tide; this distance varies with location in the estuary and with tide strength.

$\Delta t$. The quasi-steady-state period, which is a multiple of a tidal cycle and designates the duration of tracer injection and also the interval of data collection. 
HYDROLOGY OF TIDAL STREAMS

\title{
TRACER SIMULATION STUDY OF POTENTIAL SOLUTE MOVEMENT IN PORT ROYAL SOUND, SOUTH CAROLINA
}

\author{
By F. A. Kilpatrick and T. R. Cummings
}

\begin{abstract}
A tracer study was conducted in Port Royal Sound to simulate the movement and ultimate pattern of concentration of a solute continuously injected into the flow. A total of 750 pounds of Rhodamine WT dye was injected by boat during a period of 24.8 hours in a line across the Colleton River. During the following 43 days, samples of water were taken at selected points in the sound, and the concentration of dye in the samples was determined by fluorometric analysis.

The data obtained in the field study were used with theoretical models to compute the ultimate pattern of concentration of nonconservative and conservative solutes for a hypothetical continuous injection at the site on the Colleton River.
\end{abstract}

\section{INTRODUCTION}

This report describes a study of the movement of injected solutes in Port Royal Estuary in South Carolina. This study was conducted as a part of a comprehensive investigation of the physical, chemical, and biological characteristics of the waters of this estuary.

The estuary consists of a broad, deep channel, which is 3 miles wide at the confluence with the ocean, four tributary rivers (the Broad, Chechessee, Beaufort, and Colleton), and small channels which interconnect the estuary to other coastal waters. (See fig. 1.) The estuary is filled primarily with ocean water because of the relatively small volume of fresh-water inflow.

The objective of this study was to simulate the movement and the ultimate pattern of concentration of a solute continuously injected into the Colleton River at a point 13.75 miles upstream from the ocean. The objective was attained by a combination of field tests and 


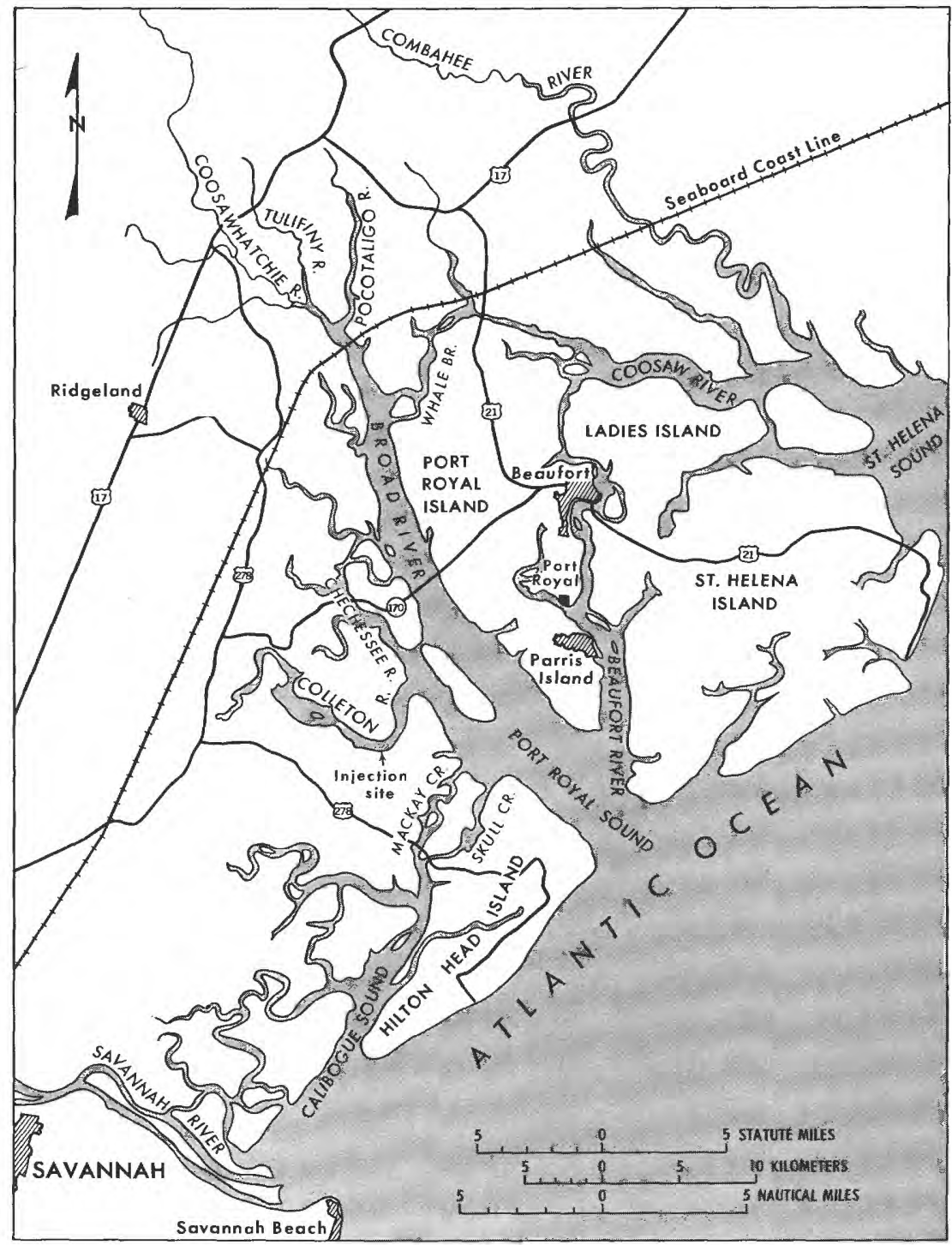

FIgURE 1.-Map of Port Royal Sound and vicinity.

theoretical analysis. Rhodamine WT dye was injected into the Colleton River during a period of 24.8 hours, and the movement of the dye in the estuary was traced during the following 43 days. This information when used with the principle of superposition permits the computation of the pattern of concentration that would exist at any time for alternate rates of injection of solutes at the site on the Colleton River. 


\section{ACKNOWLEDGMENTS}

A study of this magnitude required at one time or the other, the services of most of the personnel of the U.S. Geological Survey in South Carolina. In addition, support came from colleagues ir Washington, D.C., and Atlanta, Ga. The South Carolina Water Resources Commission aided significantly in taking aerial photographs and provided other supporting services. The U.S. Marine Corps Parris Island, S.C., and the South Carolina Fish and Wildlife Service supplied men and boats when needed. The assistance of all these agencies and their personnel is gratefully acknowledged.

\section{METHOD OF STUDY}

Several tools are available to evaluate the movement of solutes introduced into a watercourse: mathematical models and tracersimulation methods are commonly used. The first method mathematically combines the flow and dispersion characteristics of the estuary and involves extensive hydraulic calibration of the estuary.

The second method, the subject of this report, involves sirculating the movement of a waste solute by injecting a fluorescent dye tracer into the watercourse. The chief advantage of the method is that the tracer imitates exactly the movement of a like solute without the necessity of measuring the various hydraulic parameters of the estuary.

The principle of superposition on which this method is based can be better understood if the case of continuous injection into a flowing stream is considered first. If, as shown in figure $2 A$, a slug of tracer, $W_{a}$, is injected instantaneously into a flowing stream, the timeconcentration relation at an observation point $X$ downstream is defined by a typical bell-shaped curve. This curve represents the response to a single slug injection or impulse. If slug injections of the same amount of tracer are repeated at uniform, closely spaced time intervals, concentration builds up to some ultimate plateau lovel. A series of closely spaced slug injections thus amounts to a continuous injection and yields an ultimate concentration level dependent on the stream discharge and the amount or rate of tracer injection. The ultimate level, $C_{B_{x}}$, as shown in figure $2 A$, may be simulated by superimposing concentrations from a series of unit response curves, a method of computation described by Linsley, Kohler, and Paulhus (1958) under unit hydrograph theory; or it may be simulated by numerically integrating the response curve produced by a single slug injection.

A more complex situation exists in an estuary because of alternate directions of tidal flow, seaward and shoreward, and beceuse of fresh-water inflow. Thus, the response curve resulting from an instan- 


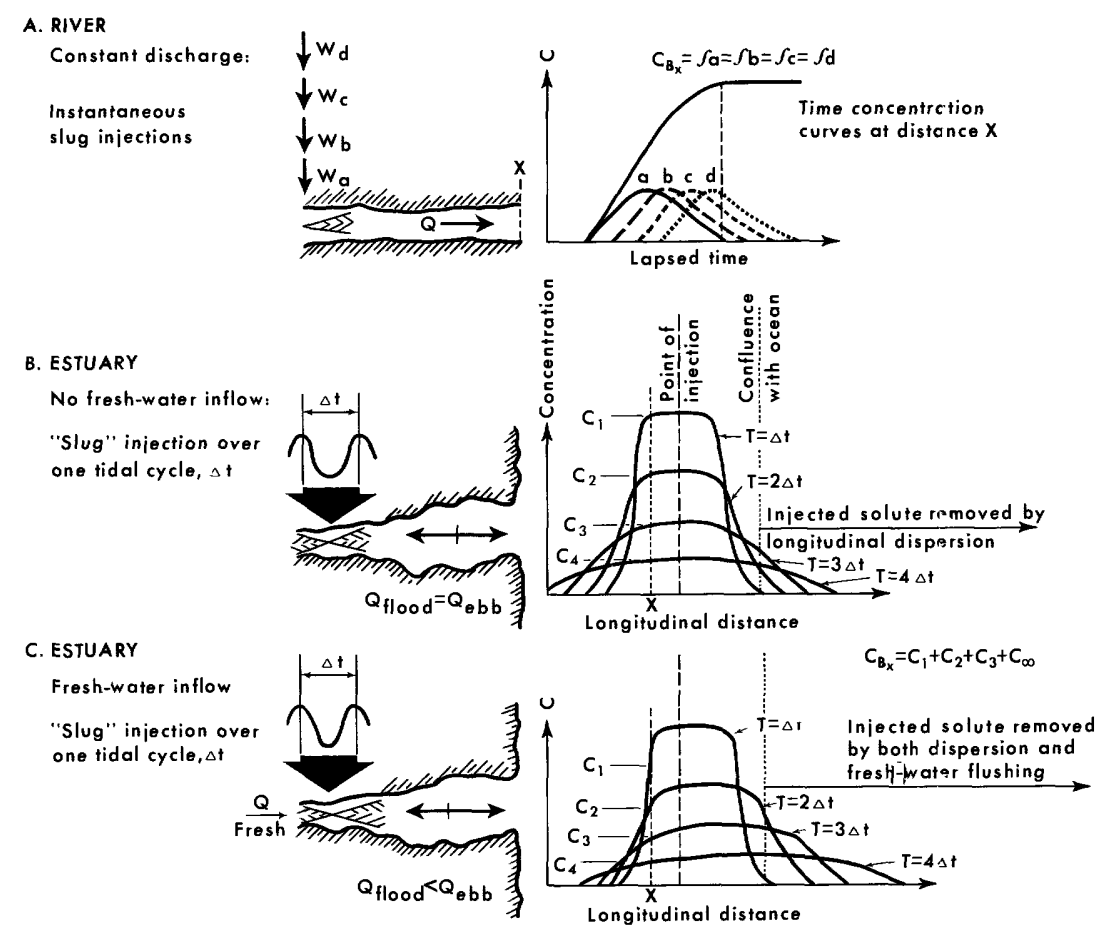

FIgURE 2.-Illustration of superposition principle as applied to rivers and estuaries.

taneous slug injection in an estuary would vary in shape, magnitude, and location, depending on the flow condition existing when the injection was made. A whole series of different response curves could be obtained at any time during the normal 12.4-hour tidal cycle. This problem is best circumvented by assuming a tidal cycle represents a quasi-steady-state period. The tracer is then injected continuously over at least one tidal cycle, $\Delta t$ (see fig. $2 B$ ), and the resulting timedistance relations (response curves) are observed at one-tidal-cycle intervals. This tidal-cycle-long injection may still be considered a slug injection because the conditions are quasi steady state in relation to the long observation period.

For an estuary where there is no fresh-water inflow (see fig. $2 B$ ), the response curve observed at $T=1 \Delta t$ shows the tracer cloud at the end of the injection, when the tidal condition is the same as it was at the beginning of the injection. The tracer mass remains centered about the point of injection in the absence of fresh-water flow, even though it becomes more elongated with each tidal period. Some tracer is flushed eventually into the adjoining ocean, principally by longitudinal dispersion. 
If the injection point is close to the ocean and the tidal excursion is sufficiently long, a part of the tracer injected on the ebb tide may reach the ocean and be flushed out. Such flushing would cause additional attenuation of the seaward side of the cloud and the formation of a nonsymmetrical cloud.

The response curves shown in figure $2 B$ for various tidal-cycle intervals result from a single tidal-cycle-long "slug" injection. It may readily be visualized that the response to a continuous injection may be simulated by merely summing these response curves. Thus the curve at $2 \Delta t$ is the response to injection which took place two tidal cycles previous; the curve at $3 \Delta t$ is the response due to injection three tidal cycles ago; and so on. The ultimate concentration at any location $X$ may be obtained by summing each concentration observed at $\Delta t$ intervals. This summation is, in essence, the principle of superposition used by Yotsukura (1968), Bailey, McCullough, and Gunnerson (1966), and Hubbard and Stamper (1972). The principle of superposition has also been used in tracer well tests (Webster and others, 1970) and in chemical process engineering (Levenspiel, 1962). As figure $2 B$ shows, the rate of concentration buildup is rapid until the tracer cloud has become reduced and elongated by dispersion.

In estuaries where steady fresh-water inflow exists, the response curves are shifted seaward (see fig. $2 C$ ); furthermore, the concentrations may be reduced by both fresh-water and ocean-water dilution. The ultimate concentrations that would result from a continuous injection may still be computed using the superposition principle by summing the response curves. The measured-response curve reflects both the effects of fresh-water transport and the tidal dispersion and flushing and therefore shows exactly the concentration distribution of a potential waste solute having similar characteristics. Fresh-water inflow may reduce the concentration buildup at certain locations, and facilitate earlier flushing, as may be seen in figure $2 C$.

\section{STUDY AREA}

Figure 3, a detailed hydrologic map of Port Royal Sound, shows the extremely complex waterway network of the sound, the locations of data collection points pertinent to the study, and some typical velocities in the estuarine system. Mileages from the mouth of the sound upstream along the flow thalweg lines are shown for reference purposes.

This estuary is virtually undeveloped at the present time (1970). Aside from oyster boats and pleasure craft navigating the intercoastal waterway via Skull Creek and the Beaufort River, only limited ship traffic exists on the Beaufort River to the town of Port Royal. Parris Island Marine Base occupies the lower part of the island 


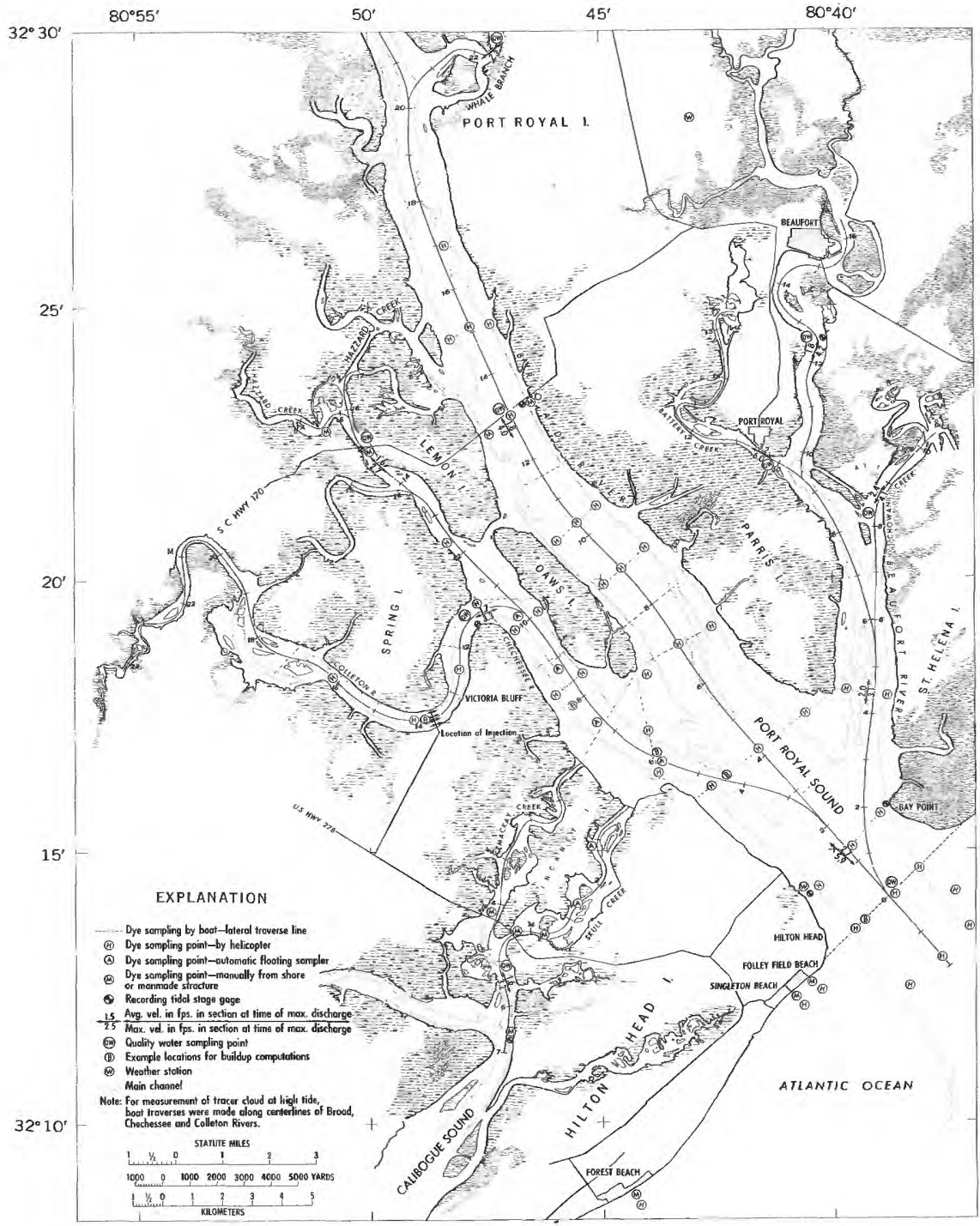

Figure 3.-Hydrologic map of Port Royal Sound.

just to the south of the town of Port Royal. Hilton Head Island on the south bank bordering the Atlantic Ocean is extensively developed as a resort area. Summer homes and camps are scattered along most creeks and waterways that branch off the sound.

TYPE OF ESTUARY

Mean depths in the estuary range from about 40 feet near the confluence with the Atlantic Ocean to 20 or 30 feet in the upper Broad, 
Chechessee, Beaufort, and Colleton Rivers. The mean tidal range in the sound is 7.5 feet, but the tides are occasionally in excess of 9 feet.

The principal source of fresh surface water into the sound is the Coosawhatchie River, for which 19 years of record show an average flow of less than 300 cubic feet per second. No significant amount of fresh water enters the other arms of the estuary. Because depths are great and tidal ranges are large, vertical mixing of the small amount of fresh-water inflow is inferred to be rapid. In the absence of major fresh-water inflows, the contents may be expected to be almost all sea water. Sea water immediately off the South Carolina coast has a specific conductance of about 45,000 micromhos. As can be seen from figure 4, which shows the measured range in specific conductance, dissolved oxygen, and $\mathrm{pH}$ during one tidal cycle at selected locations in Port Royal Sound, high values of specific conductance exist throughout the estuary. The lower values in the upper reaches indicate some dilution by fresh water.

Fresh ground-water discharge into the estuary and fresh surfacewater inflow may be the source of this minor dilution. The piezometric surface of the principal artesian aquifer ranges from about 10 feet above mean sea level near the upper reaches to about mean sea level near the mouth. The top of this aquifer occurs at elevations ranging from -50 feet mean sea level to -100 feet mean sea level in the study area. Overlying this aquifer are several shallow waterbearing units, some of which crop out in the deeper parts of the estuary and have a limited areal extent or distribution.

The specific-conductance data also showed no significant vertical variation and thus indicate a very homogeneous, well-mixed cstuary. The dissolved-oxygen concentrations were also found not to vary significantly vertically, a fact confirming estuarine homogeneity. The absolute values of dissolved oxygen also confirm the lack of pollution.

\section{TIDAL HYDRAULICS}

The stage and estimated discharge hydrographs for the Colleton River at its mouth at the start of the tracer test (fig. 5) show a normal semidiurnal type of reversing current, with flow seaward or downstream (ebb tide) for approximately 6.2 hours and then upstream (flood tide) for about 6.2 hours. High or low tide (stage) precedes slack water, or the time of zero current, by about 2 hours. A tidal day is composed of two high tides and two low tides and is approximately 24.8 hours long. In Port Royal Sound the two high tides and two low tides do not vary greatly in amplitudes. The maximum tidal discharges into and out of the Colleton River range from 100 to 150 thousand cubic feet per second. By contrast, maximum flows at the entrance to the sound, mile 0 , range from 1.5 to 2 million cubic feet 


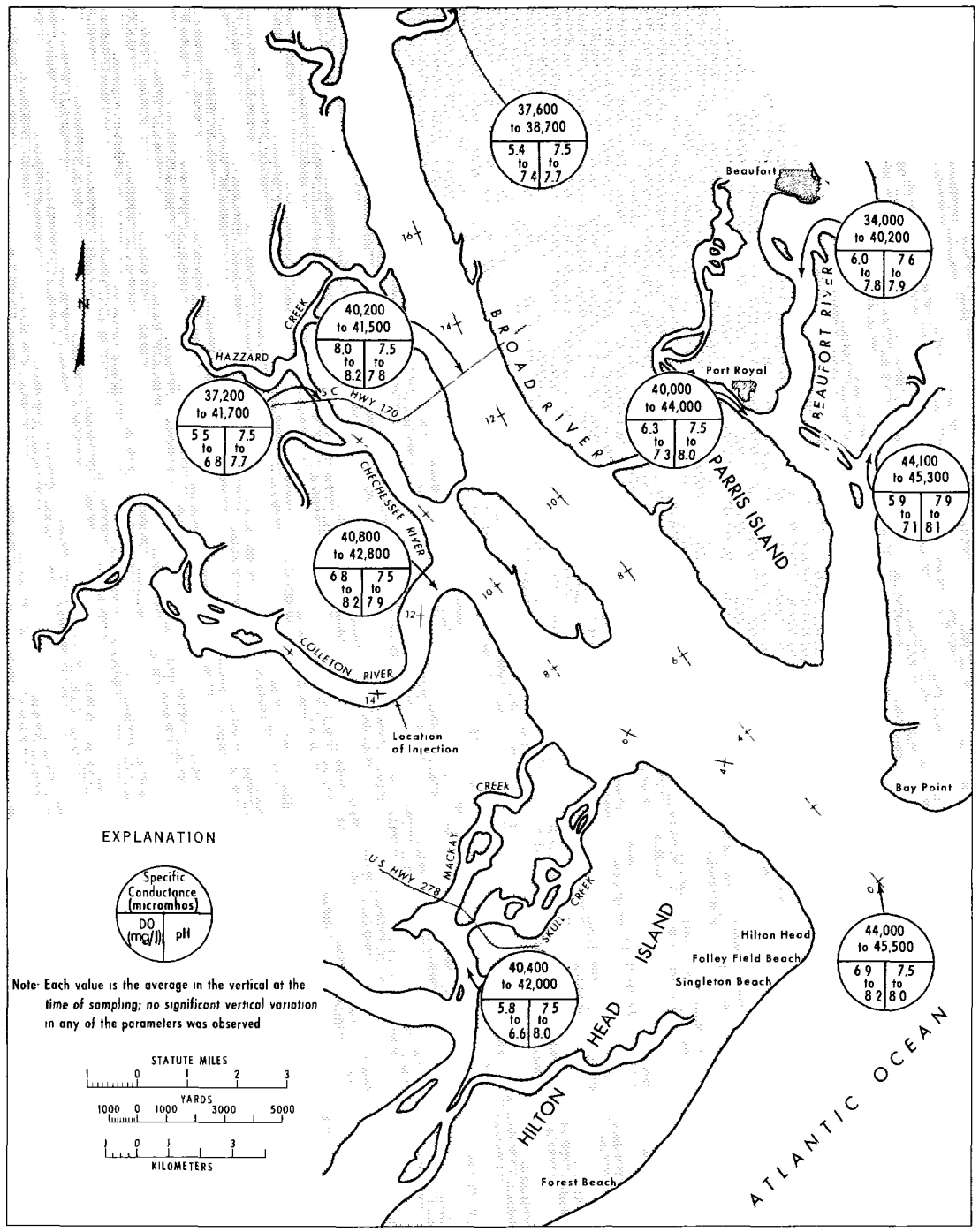

Figure 4.-Maximum variations in specific conductance, dissolved oxygen, and $\mathrm{pH}$ during one tidal cycle at selected locations in Port Royal Sound.

per second. These discharge values are based on actual measurements made in the summer of 1970 throughout the estuary. The areas under the discharge hydrograph sketched in figure 5 indicate that tidal volume exchanges at the mouth of the Colleton River are on the order of $2 \times 10^{9}$ cubic feet. These large volumes represent we.ter moving into and out of storage in the main channel, and in marshy areas upstream, and vary with absolute tidal stage. Such large tidal flows 
TRACER MOVEMENT DURING INITIAL INJECTION

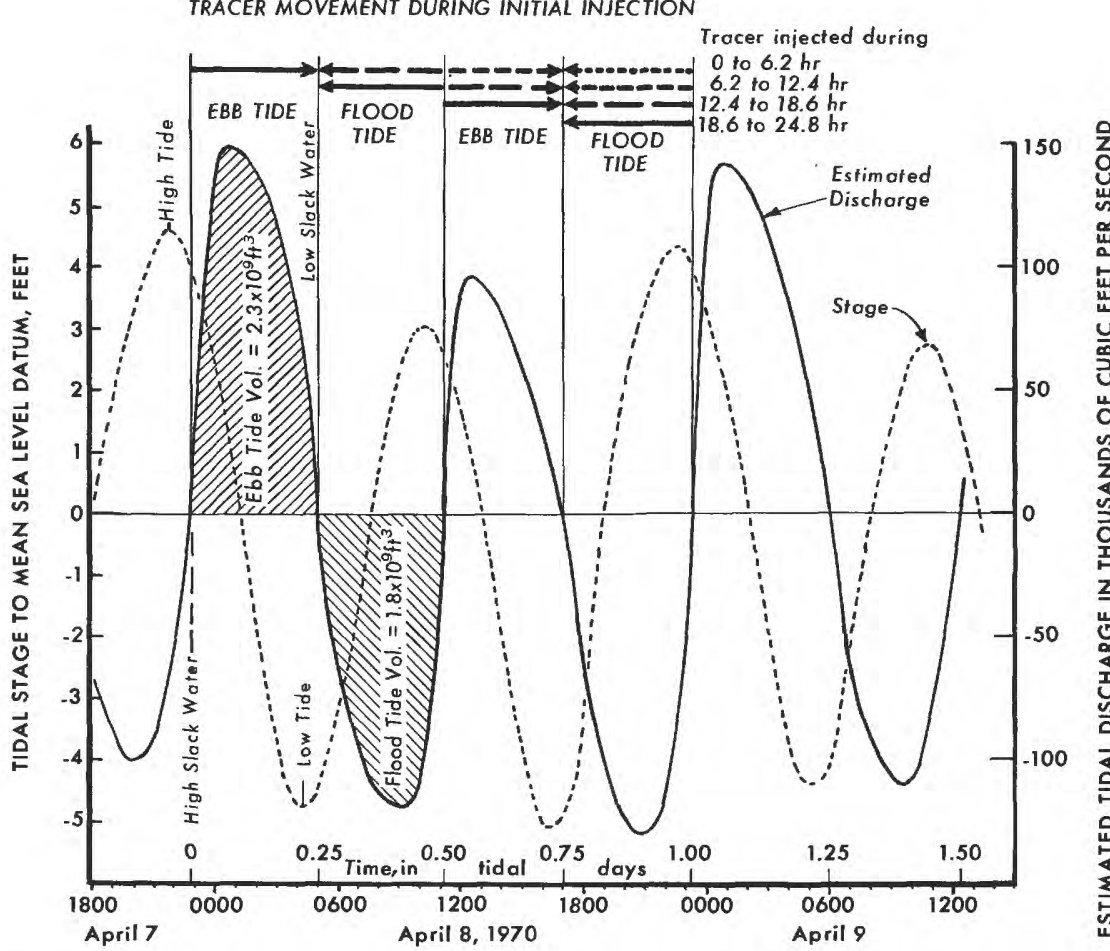

FIGURE 5.-Recorded stage and estimated discharge hydrographs for Colleton River at confluence with the Chechessee River showing tracer injection schedule and initial movement.

produce comparably large tidal velocities; some (fig. 3 ) are in excess of 6.0 feet per second.

The flow pattern in Port Royal Sound is complicated by the many interchanges with adjoining waterways. As seen in figures 1 and 3, the sound is connected with the Coosaw River and with St. Helena Sound by Whale Branch and by the Beaufort River on the east and with Calibogue Sound by Mackay and Skull Creeks to the southeast. Many smaller connections exist throughout the system, and at extreme high tide much of the region becomes a common lake. In each of these connecting waterways, tidal-flow null points exist, varying in location with wind direction and absolute tide stage.

\section{TRACER TEST}

\section{TRACER INJECTION}

Application of the superposition principle in simulating the continuous injection of a solute into an estuary is best accomplished by injecting the tracer continuously over at least one tidal cycle. This 
quasi-steady-state period, $\Delta t$, also determines the sampling interval. As can be seen in figure 5, amplitudes of the first and second tidal cycles differed on April 8, 1970. While this nonuniformity was not great, continuous injection over two tidal cycles would assure more quasi-steady simulation and permit the observation interval to be greater. For this reason, $\Delta t$ for the actual test was chosen as 24.8 hours, or a tidal day.

From 2240 hours on April 7, 1970, to 2320 hours on April 8, 1970 (see lower abscissa of fig. 5), a total of 750 pounds of Rhodamine WT dye, a fluorescent water-soluble tracer, was injected by boat across the Colleton River at mile 13.75. Ten pounds of dye was poured out every 20 minutes in a line injection (fig. $6 A$ ). This dye has a specific gravity of 1.19 , but because of its high solubility and the existing turbulence of the water, it mixes rapidly into the flow. Injection began with the start of ebb tide, $T=0$, and ceased one tidal day later. From $T=0$ to 0.25 and from 0.50 to 0.75 tidal days, the tracer moved seaward; from $T=0.25$ to 0.50 and from 0.75 to 1.00 tidal day, flood tide carried the tracer upstream in the Colleton River. Figure $6 B$ is an aerial view during flood tide (about 1000 hours on April 8) showing the individual line injections moving upstream. These tracer lines soon dispersed longitudinally in such a manner that, within a few miles, they overlapped and became indistinguishable as separate clouds, much as illustrated in figure $2 A$.

\section{SAMPLING}

The aerial photograph (fig. $6 B$ ) taken on the flood tide shows that the surrounding marshland is extensively flooded at high slack water. At such times the tracer cloud may be spread over many square miles of inaccessible swamp. At low slack water, conversely, water and the tracer cloud drain out of the marshlands and occupy the more accessible, more confined main channels. For this reason, and because of the experience of others (Dyar and others, written commun., 1968) in measuring a tracer in an estuary, it was decided to measure primarily at low slack water. Tracer cloud observations shown in figure 7 have been made mostly at low slack water, but a few high-slackwater measurements were made periodically to define the outer limits of the tracer cloud.

Figure 7 shows the dye injection and subsequent sampling schedule for the first 2 weeks. Thereafter the frequency of sampling decreased, with the last samples being collected on May 20, 1970, at $T=41.25$ tidal days after the start of injection.

The tidal discharges shown in figure 7 are estimated from stage record to show relative magnitudes between cycles for the initial 2 week period. Dye injection and initial sampling took place during a 


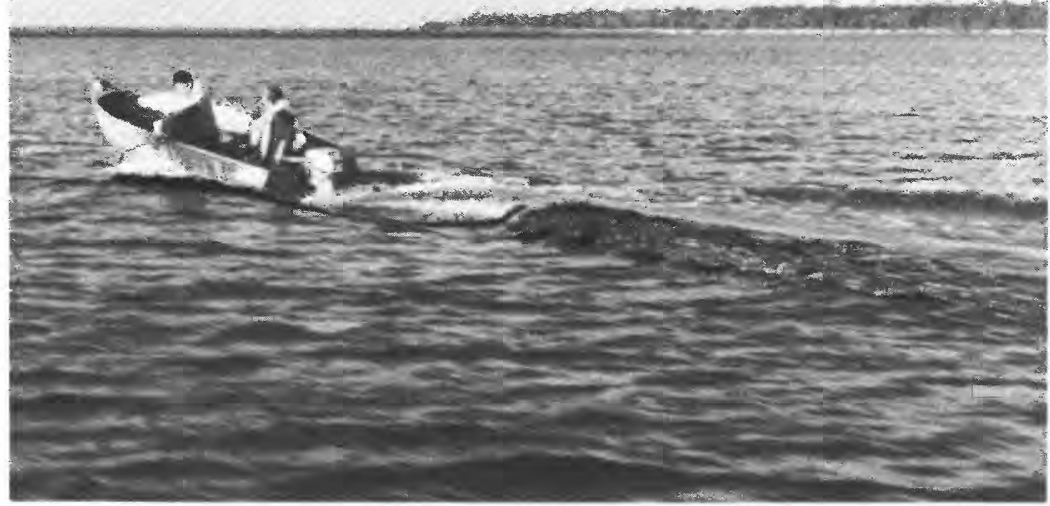

A. - Line injection of dye tracer by boat across Colleton River at mile 13.75; view is eastward in direction of Port Royal Sound; Victoria Bluff is on the right bank, and low marshland is visible on the left bank.

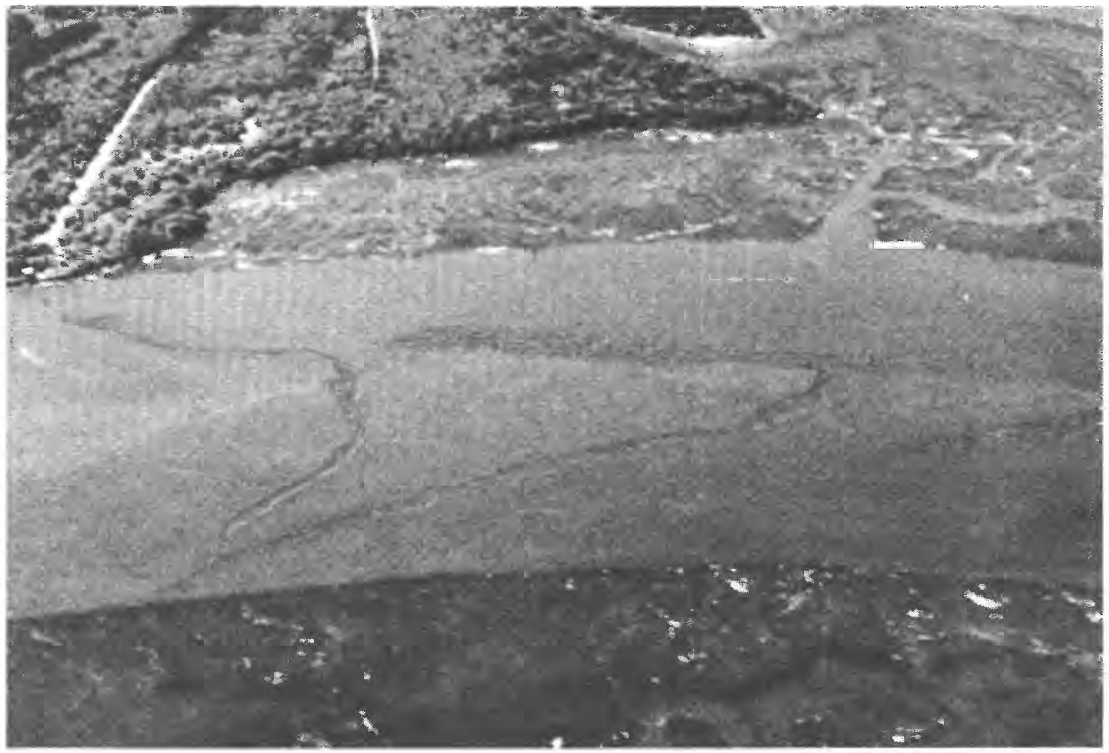

B.-Aerial view of dye injection on the Colleton River; line of tracer is being distorted and swept upstream on the flood tide; view is southward; access road is visible at top of picture. 
- Low slack water samples

O High slack water samples

NOTE: Discharge positive

in seaward direction

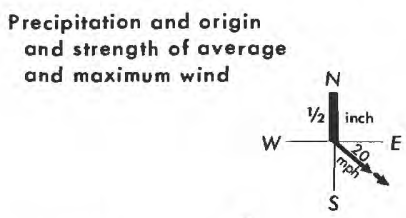

Precipitation and origin

and strength of average
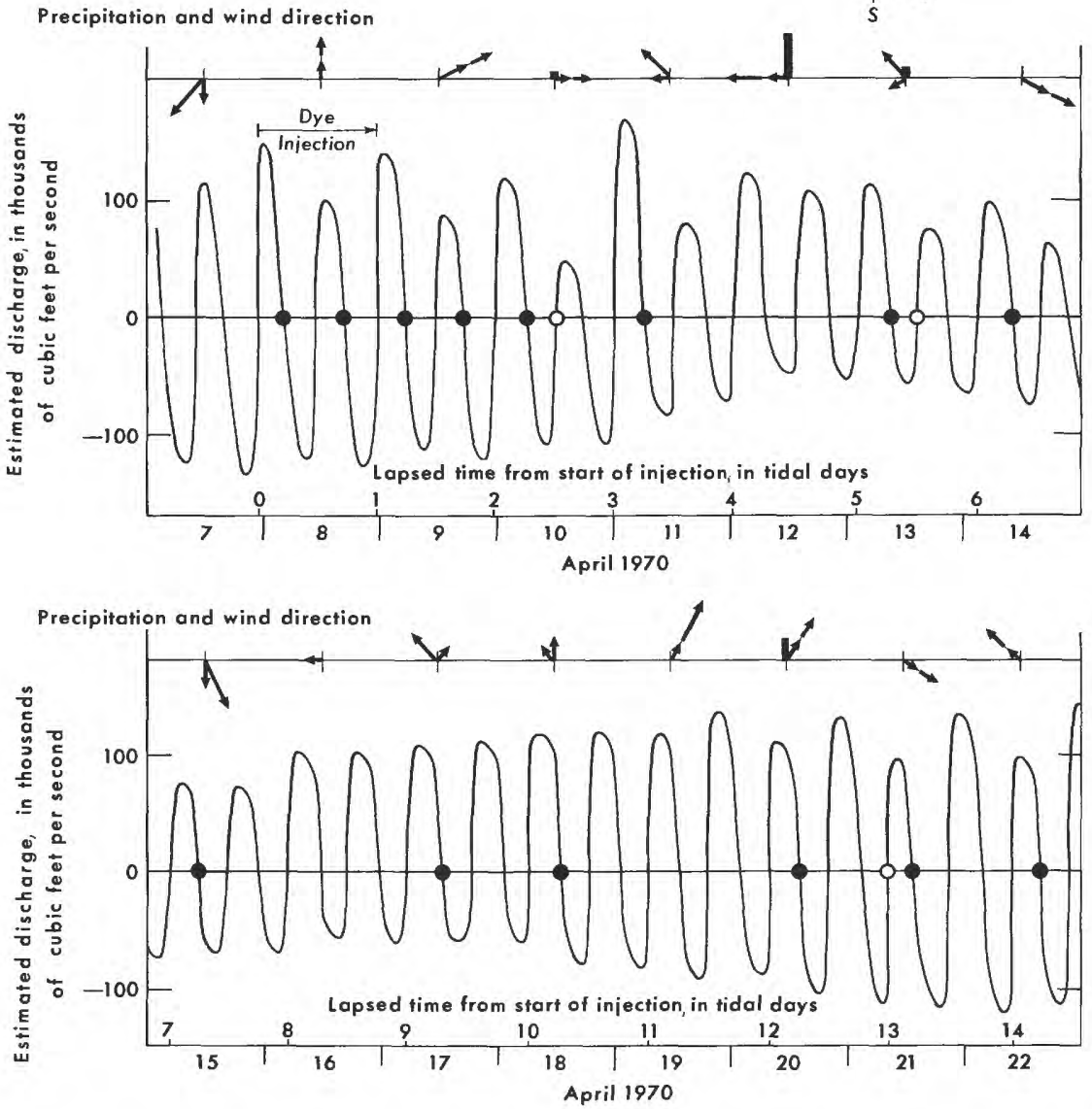

FIGURE 7.-Precipitation, and wind direction and strength, for Port Royal Sound; estimated discharge hydrograph for Colleton River showing injection and sampling schedule for the first 2 weeks of the tracer test.

period of relatively large-amplitude tides (fig. 7). Tidal amplitueds subsequently diminished and then grew large again. That similar cyclic tidal amplitude variations were experienced through May 20 indicates that a representative period was chosen for the tracer simulation test. The same may be said for other climatic conditions experienced during the test period (see fig. 7), such as rainfall, and wind direction and speed. April 8 was chosen for the injection also because the occurrence of low slack water during the daylight hours for the next 3 weeks expedited the sampling of the tracer cloud. 


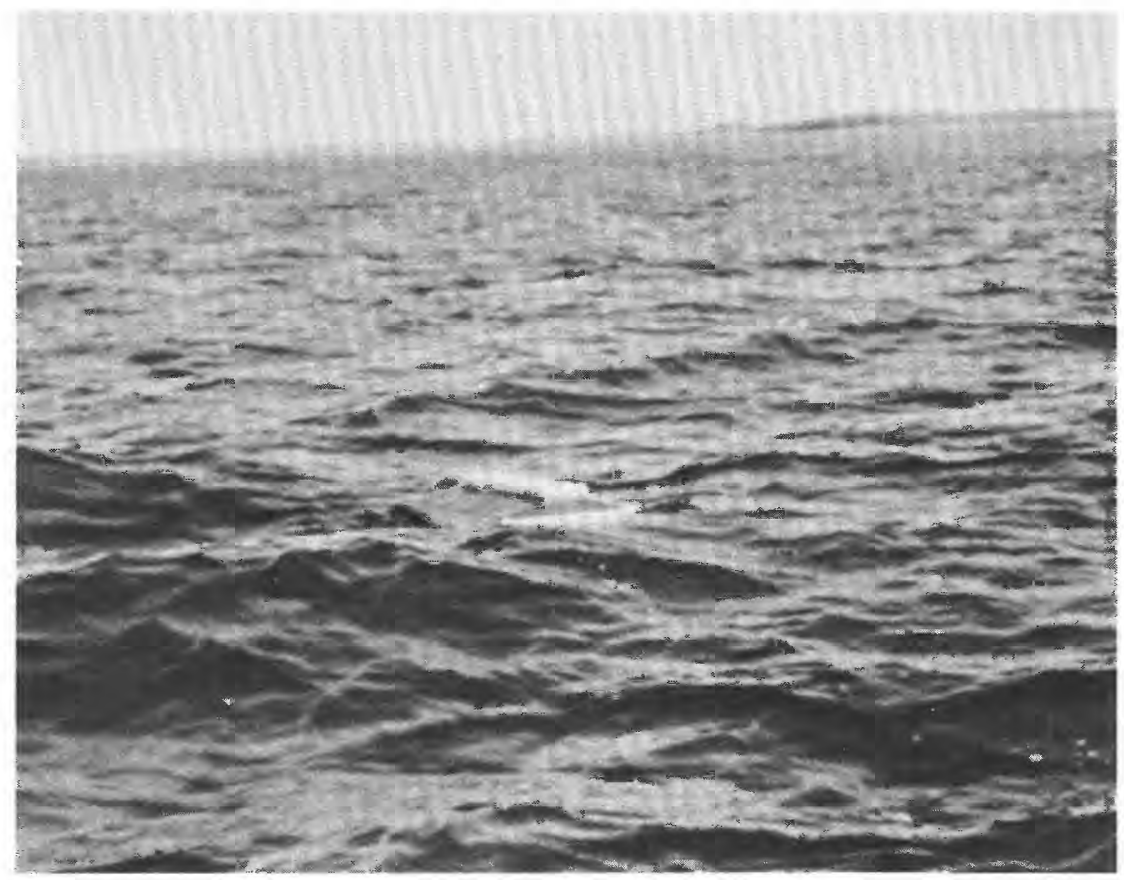

Figure 8.- One of several automatic floating samplers utilized to sample dye-tracer cloud at night and under hazardous conditions; samplers were anchored at desired locations and set to sample every 45 minutes.

Grab water samples were obtained by boat along the previously marked lateral traverse lines shown in figure 3. The extremities of these traverse lines were marked with large painted plywood panels supplemented with anchored buoys in the main channels. Grab samples were also taken manually from bridges, docks, and other manmade structures. Where nightime sampling was hazardous and during the first 2 days when it was desirable to observe the complete movement of the dye cloud with time, automatic floating samplers were utilized. (See fig. 8.) These units automatically collected samples at 45-minute intervals at four midchannel locations during the early morning hours of April 8 ( $T=0.25$ tidal days). They aided in defining the extent of the initial seaward movement of the tracer cloud.

The duration of low slack water, the length of time in which the tracer cloud is essentially immobile, is, for practical purposes, from 1 to 2 hours. The time of low slack water differs with location; at the mouth of the Colleton River, it occurs 20 to 30 minutes later than it does at the mouth of the sound. Grab water samples were therefore collected by starting just prior to low slack water at the downstream edge of the tracer cloud and by thereafter moving upstream with the occurrence of low slack water. 
As the tracer cloud became more dispersed and more uniform in concentration, fewer but more-widespread samples were needed. A helicopter proved to be advantageous in rapidly collecting samples over what eventually amounted to 50 square miles of water.

\section{LABORATORY ANALYSIS}

The large number of water samples collected and the need for concurrence in their analyses so that subsequent sampling could be scheduled dictated that a laboratory be located near the study area. A Turner 111, filter-type fluorometer and a precise temperature bath, along with supporting laboratory accessories, were conveniently located at a motel on Hilton Head Island.

The fluorometer measures concentration by measuring fluorescence; the principles and techniques of its use are described by Wilson (1968). Dye standards were carefully prepared in duplicate from distilled water from a sample of the dye retained for this purpose. The fluorometer was completely calibrated several times during the study, with frequent intervening checks. New dye standards were prepared at the end of the test as a double check, and the fluorometer calibration was determined anew. No significant calibration variations were observed.

Samples were brought to the laboratory immediately, placed in the temperature bath, and analyzed within 12 hours or less of collection. As the test progressed and concentrations became low, samples were allowed to settle for at least 24 hours in the temperature bath prior to fluorometer analysis to lessen background interference due to sediment. As a result of careful fluorometric techniques, dye concentrations were determined to be accurate within $\pm 0.02 \mu \mathrm{g} / \mathrm{l}$.

\section{DATA ANALYSIS AND INTERPRETATION}

\section{LOW-SLACK-WATER ISOCONCENTRATION MAPS}

Water samples were extensively collected over the estuary from April 8 to May 20, 1970, during 25 periods of low slack water and seven periods of high slack water. These data were plotted on base maps, and lines of equal concentration were drawn to give a picture of the movement of the tracer cloud with successive tides. Seven isoconcentration maps for low-slack-tide periods are shown in figures 9 through 15 to give a picture of the initial and long-term movements of the tracer cloud.

The maximum seaward movement of the tracer cloud at the time of the first low slack water, $T=0.25$ tidal days, is shown in figure 9 . Only one-fourth of the dye has been injected and has moved downstream on the ebb tide. At $T=0.25$, movement upstream is impending. The tracer moved up the Colleton River from $T=0.25$ to 0.50 


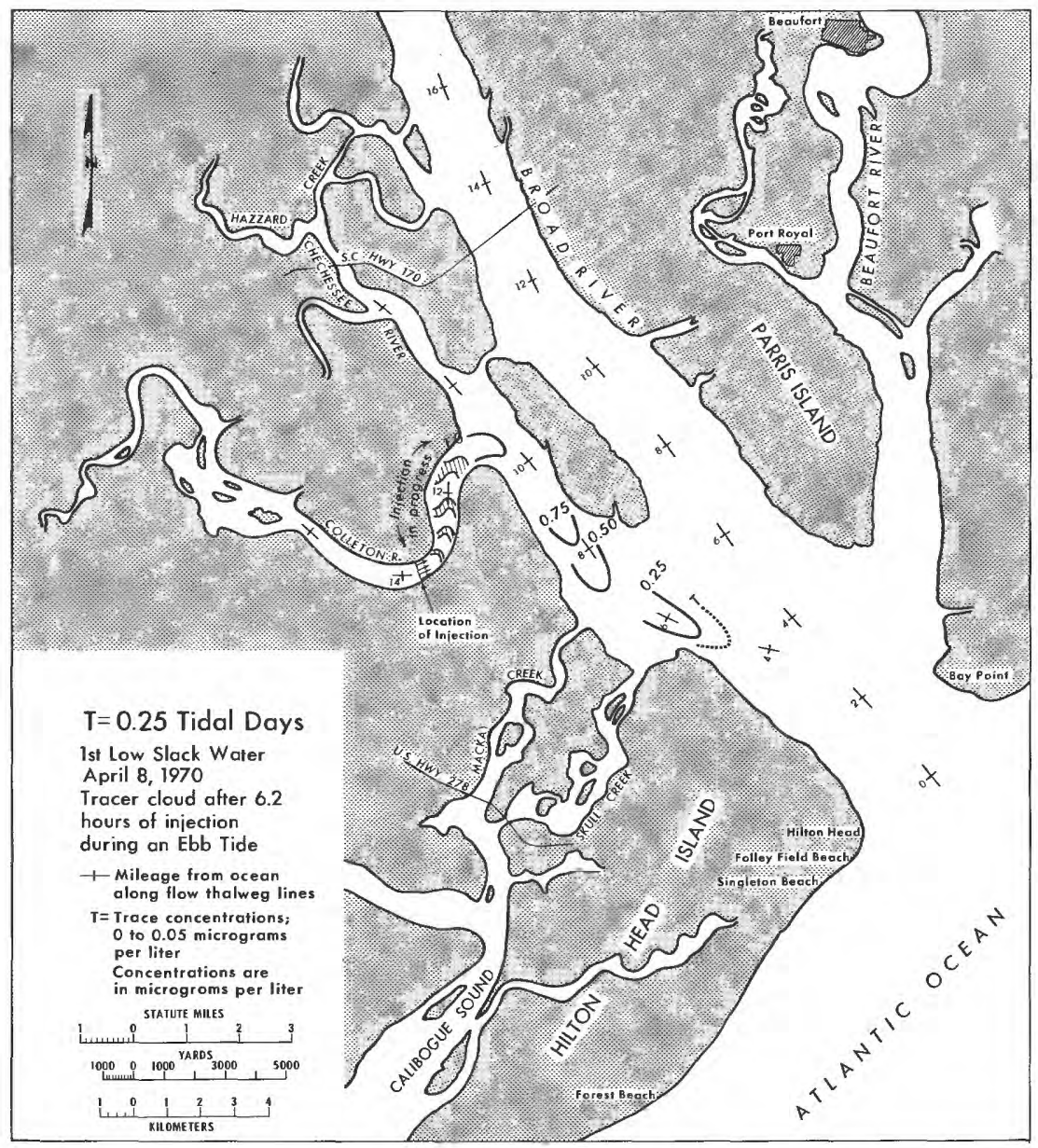

Figure 9.-Low-slack-tide isoconcentration map showing maximum seaward movement on the initial ebb tide.

tidal days. Not only does this tracer move upstream, but much of that injected during the first quarter tidal day also returns and moves upstream. Some of the returning tracer travels up the Chechessee River as well as into other small channels filled on the flood tide.

The tendency during this initial period and subsequently for the main tracer plume to favor the right bank of the Chechessee River rather than to spread uniformly across the channel is of interest. This lack of lateral dispersion and mixing between streams below their confluence is typical of inland rivers.

From $T=0.50$ to 0.75 tidal days (the third quarter), the tracer again moves seaward with the ebb tide; figure 10 shows the position 


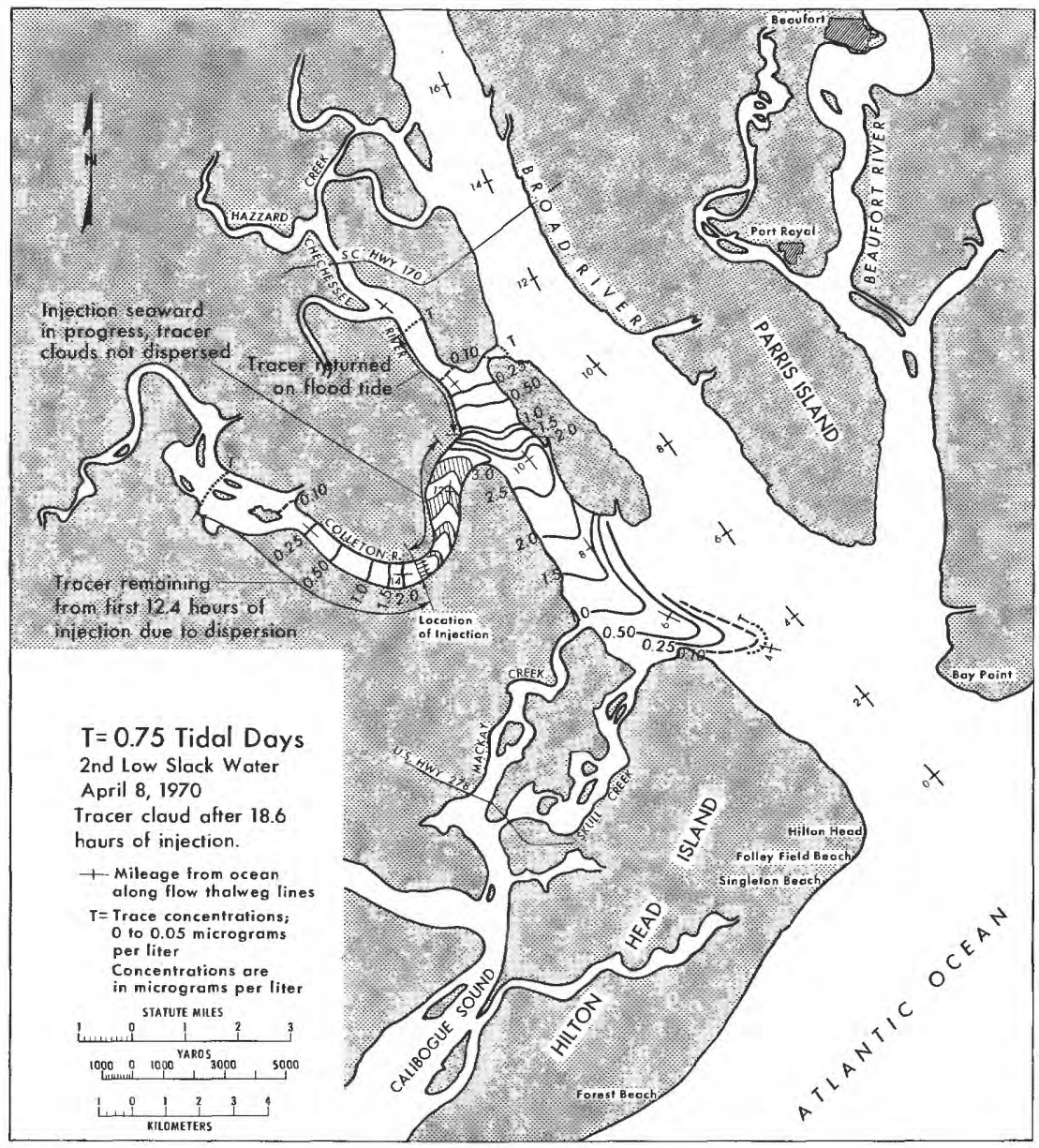

Frgure 10.-Low-slack-tide isoconcentration map showing tracer remaining in upstream reaches because of dispersion effect.

of the dye cloud at the end of this second low slack water. The leading edge of the cloud has moved seaward only slightly from its location at $T=0.25$, probably because of a weak second ebb tide. Although much of the tracer that initially moved up the Colleton River has now moved downstream along with that injected during the two ebb tides, dispersion has caused a large quantity to remain upstream from the injection point. Some tracer also remains up the Chechessee River for the same reason.

The third low slack water $(T=1.25)$ is the first following cessation of all dye injection. The location of the tracer cloud at this time is shown in figure 11. The cloud has been further dispersed seaward, 


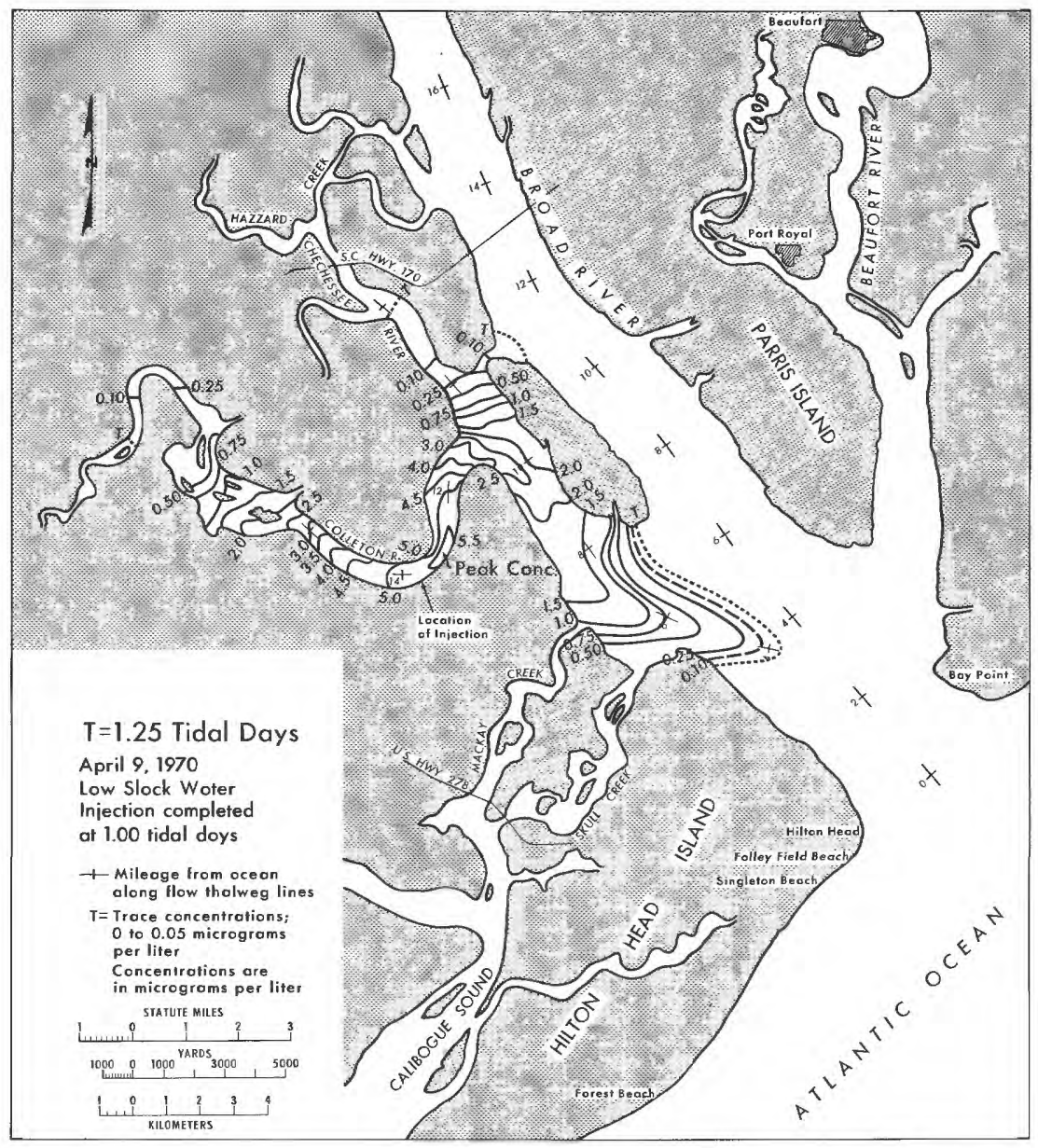

FIGURE 11.-Low-slack-tide isoconcentration map showing location and magnitude of dye cloud after injection had ceased.

and the leading edge of the cloud has begun to enter the Broad River. A significant amount of tracer is now found in the upper Colleton and Chechessee Rivers. The center of the tracer cloud mass is still located at the point of injection, and maximum concentrations of about 5.5 $\mu \mathrm{g} / \mathrm{l}$ exist just downstream from this point. Concentrations in the lower Chechessee River and at the confluence with the sound are low because of the large volumes of water available for dilution. Conversely, concentrations are relatively high in the upper Colleton River because a smaller volume of water is available for diluting the tracer which had been injected on the flood tides.

By $T=2.25$ tidal days, the tracer cloud (fig. 12) has further dispersed, and significant amounts of the dye have entered the Broad 


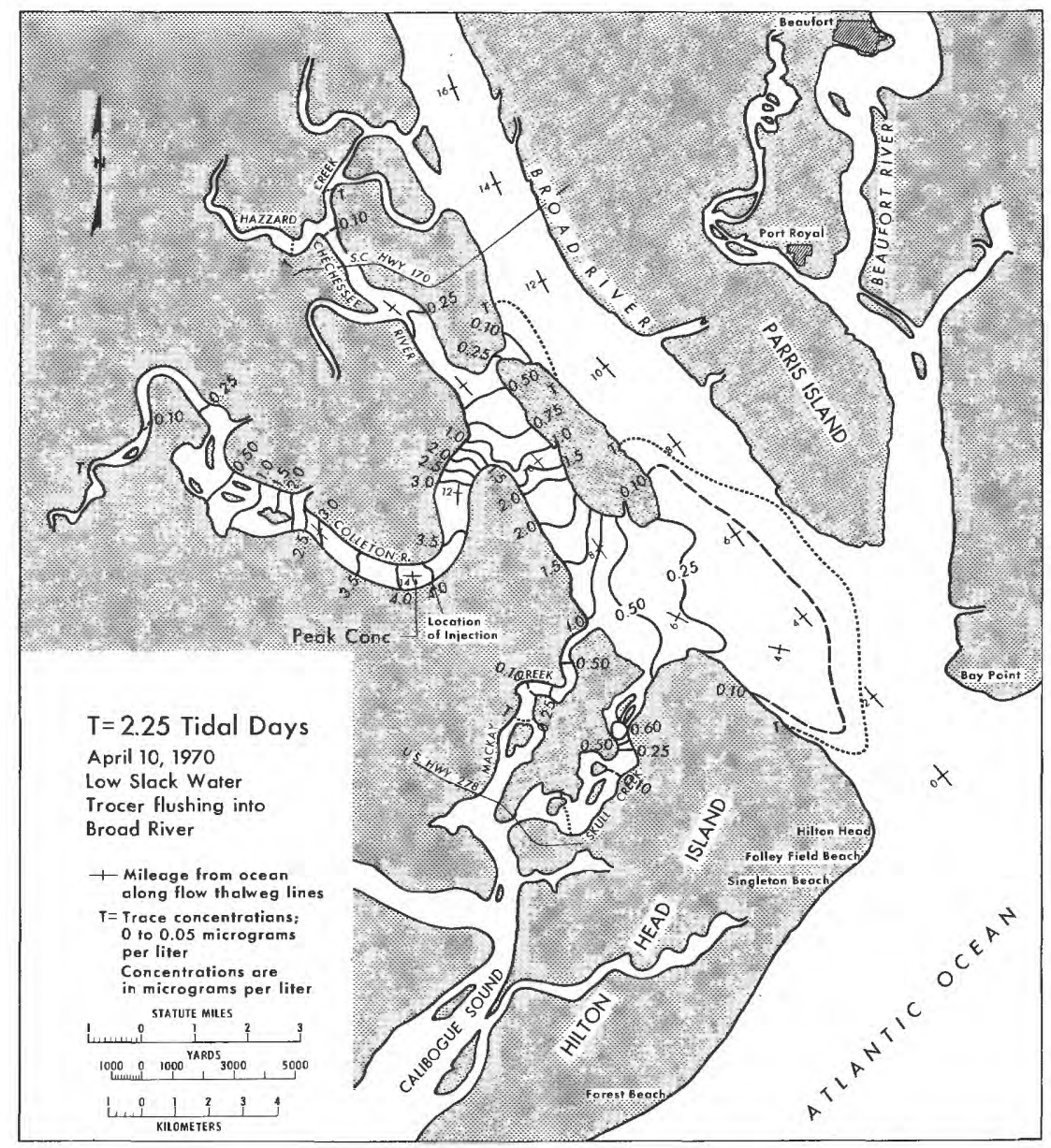

Frgure 12.-Low-slack-tide isoconcentration map showing the first significant flushing into the Broad River.

River and Skull and Mackay Creeks. The peak concentration is just over $4 \mu \mathrm{g} / \mathrm{l}$ and is just above the point of injection. Concentrations upstream in the Colleton River are relatively high as removal is by dispersion only, there being no significant fresh-water inflow to produce transport. Similarily, direct dilution by fresh-water is not occurring. Further dispersion of the tracer cloud up the Colleton and Chechessee River has occurred. Conversely, concentrations in the Broad River are very low, owing to the large quantities of water available for dilution. As was the case below the confluence of the Colleton and Chechessee Rivers, the tracer cloud favors the right bank as it moves into the lower sound. 


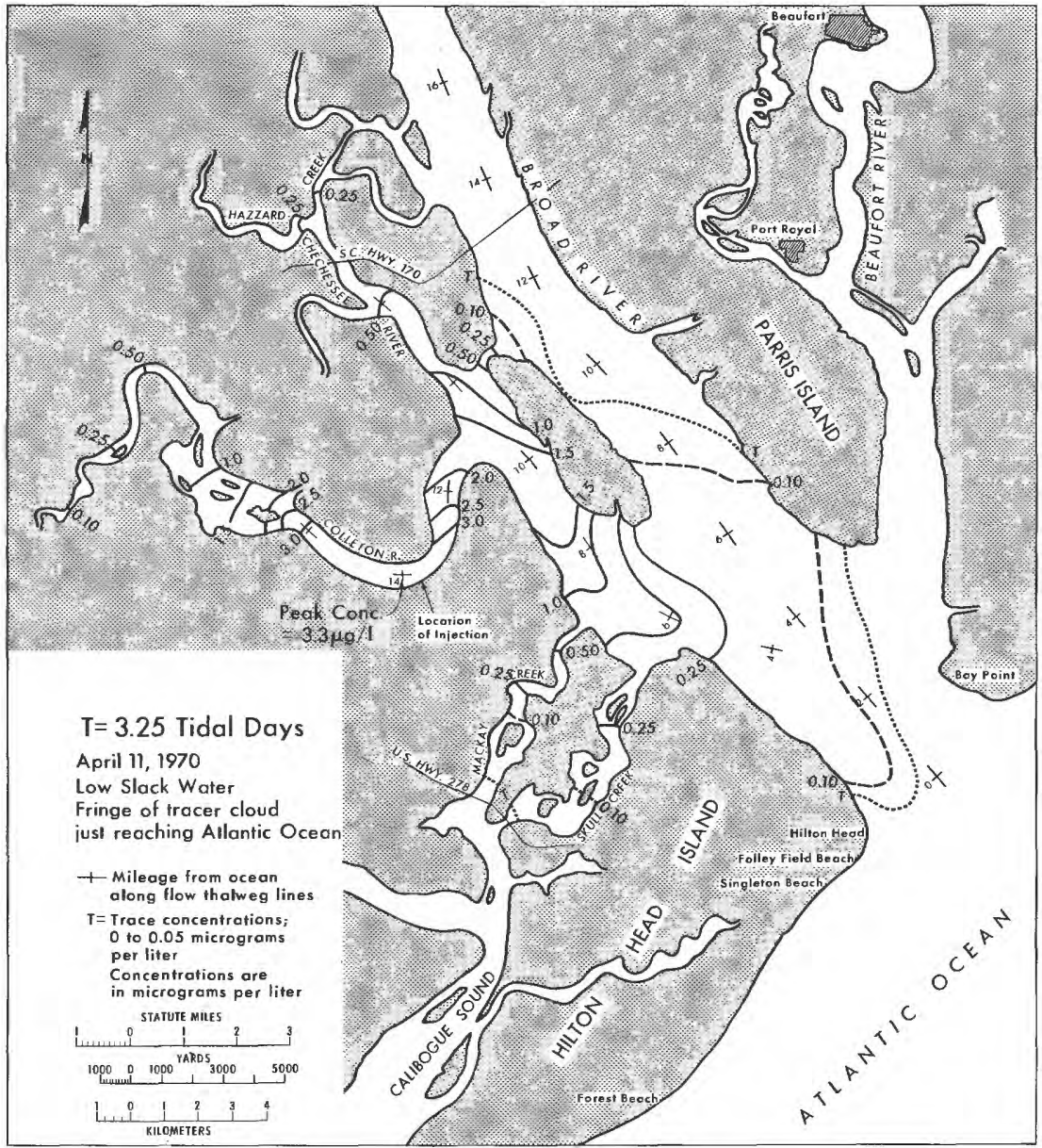

FIGURE 13.-Low-slack-tide isoconcentration map showing time and distribution of dye at first arrival with the Atlantic Ocean.

At $T=3.25$ tidal days (see fig. 13), the downstream edge of the tracer cloud has just reached the Atlantic Ocean, and hence, flushing begins at about this time. The tracer cloud has, in general, further dispersed, and the peak concentration has dropped to about 3.3 $\mu \mathrm{g} / \mathrm{l}$ just above the injection point.

By 16.25 tidal days (fig. 14), the tracer cloud has dispersed to the extent that minor concentrations exist up the Beaufort River and up the Broad River above the South Carolina Highway 170 bridge. That significant amounts of tracer have been flushed into the Atlantic Ocean is indicated by the traces (less than $0.05 \mu \mathrm{g} / \mathrm{l}$ ) of dye found along the beaches off Hilton Head Island. Since no traces of dye were ob- 


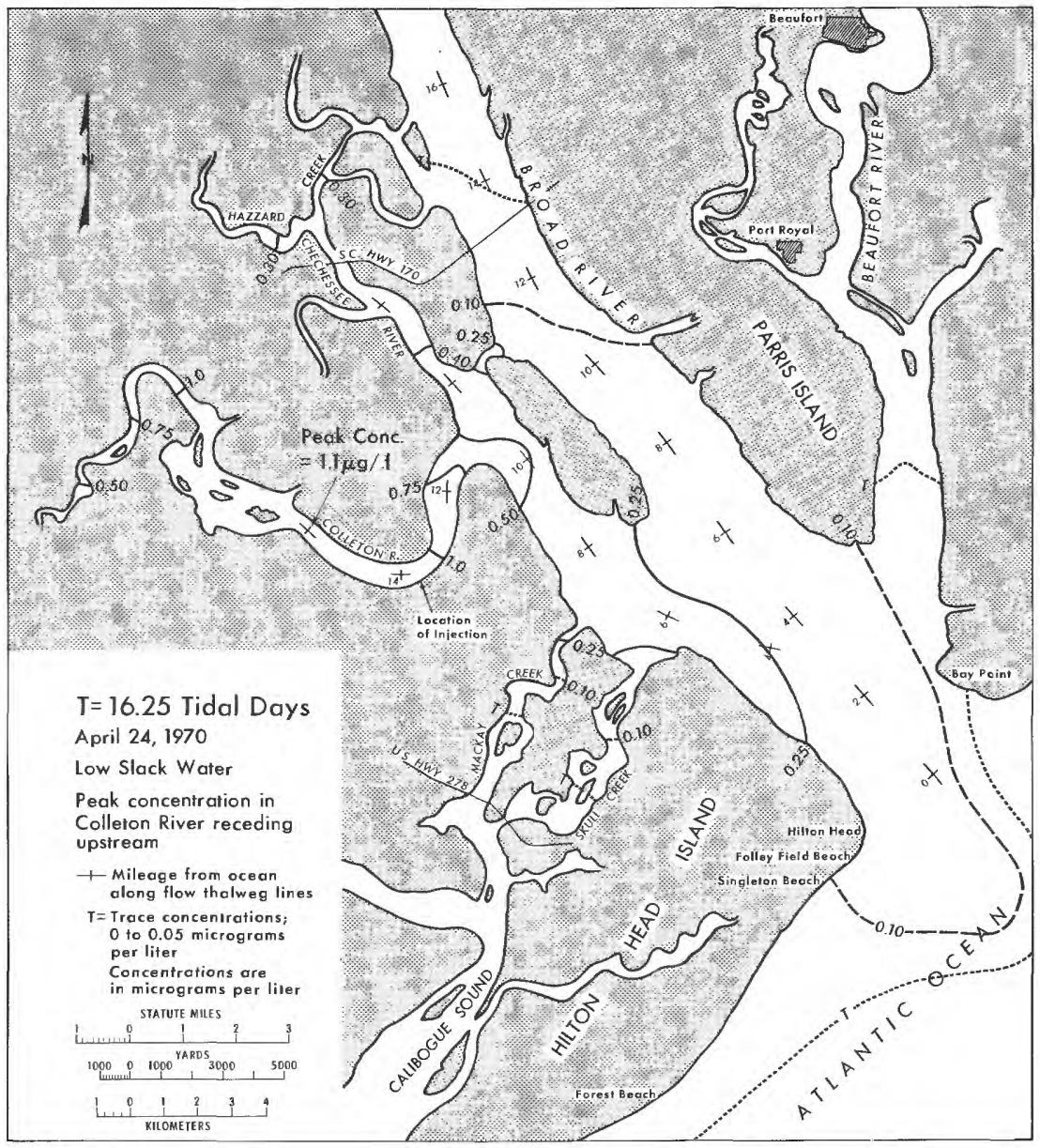

Figure 14.- Low-slack-tide isoconcentration map showing recession of peak up Colleton River.

served in the Atlantic Ocean to the northeast, the ocean currents appear to flow in a southeasterly direction at this time. Because the main channel of Port Royal Sound extends beyond the confluence of the sound with the ocean directly seaward and because shallow water is found off the beaches on both sides, (see fig. 3), most of the discharge that moves past the confluence probably flows directly out into the ocean.

By 16.25 tidal days only low tracer concentrations exist in Skull and Mackay Creeks. The concentration in Mackay Creek is lower than in Skull Creek because at high slack water, tracer disperses into the more extensive marshland areas adjoining this waterway. 
The maximum concentration at this time is reduced to slightly over $1 \mu \mathrm{g} / \mathrm{l}$ and is more than 2 miles upstream from the injection point. This inland migration of the peak continues, as may be seen in figure 15 , for $T=41.25$ tidal days. At 41.25 tidal days the peak is approximately 4.5 miles upstream from the injection point. This migration of the peak results because the shortness of the upstream reach of the Colleton River presents a physical barrier to the dispersion and dilution of the solute.

As seen in figure 15, tracer concentrations are insignificant throughout the estuary after 41.25 tidal days. Traces of dye were also found in the Broad and Beaufort Rivers at this time, but at a level of detection that did not justify presentation in figure 15 .

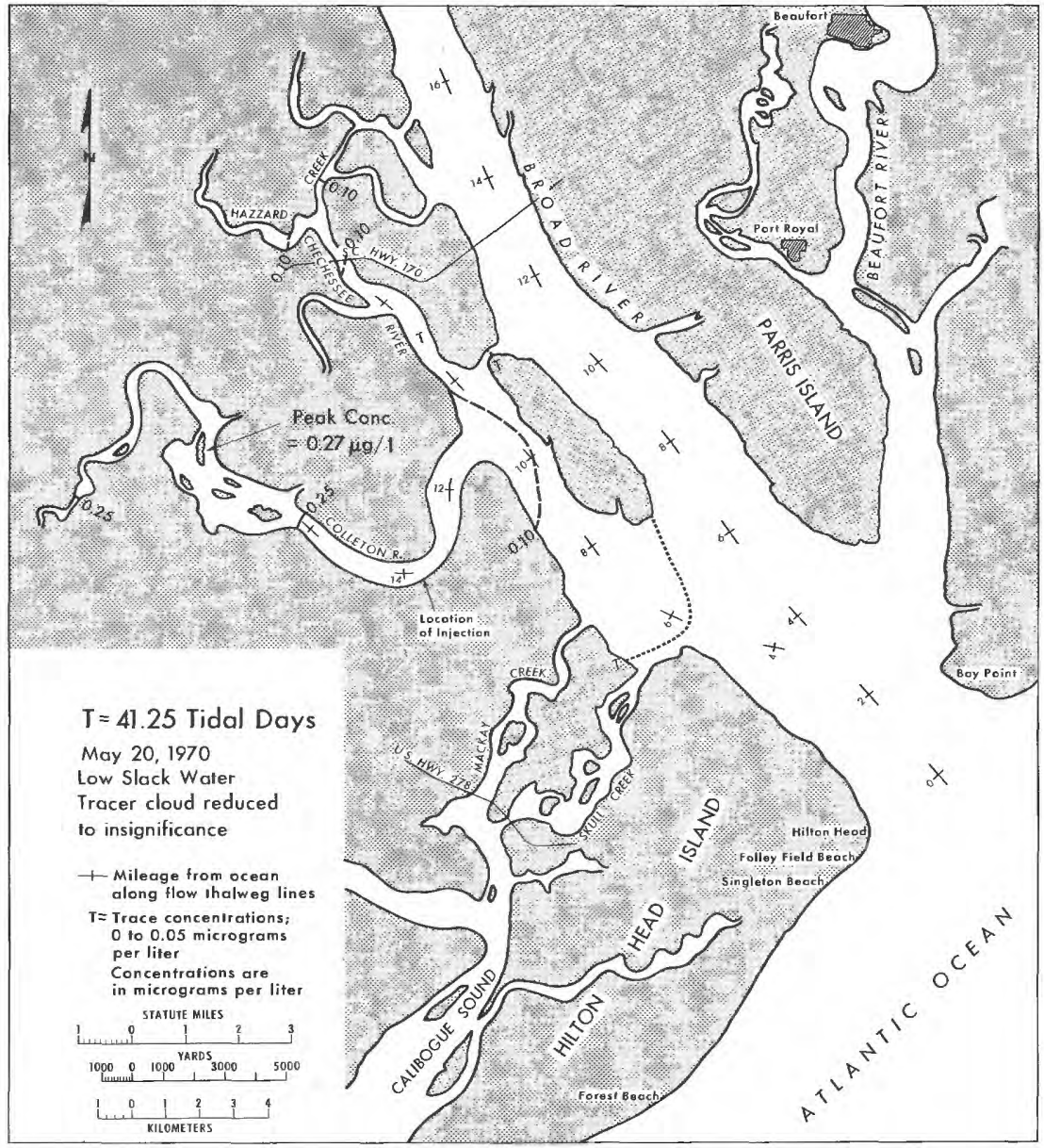

Figure 15.-Low-slack-tide isoconcentration map showing final observation of dye cloud. 


\section{HIGH-SLACK-WATER ISOCONCENTRATION MAPS}

Figures 9 through 15 show the tracer cloud at selected low-slackwater periods, or at maximum seaward positions. Water (or tracer) occupying a certain position at low slack water will move upstream with the flood tide. The position of the tracer cloud at high slack water after 16.00 tidal days is shown in figure 16 for comparison with its next low-slack-water position, which is shown in figure $14(T=16.25$ tidal days). The tidal excursion between high and low tide is about 4 miles.

\section{ULTIMATE PATTERN OF CONCENTRATION WITH CONTINUOUS INJECTION}

The ultimate concentration to be expected from continuous injection of a solute can be computed by using the superposition principle, whereby the concentration at any location resulting from a slug injection of tracer is integrated with respect to time. The area under the observed concentration-time curve for any point in the estuary thus yields the ultimate concentration at that point for a solute which is injected continuously.

Figure $17 \mathrm{~A}$ shows the observed concentration-time curves for five locations (refer to fig. 3) from the injection point to the confluence of the Broad River with the Atlantic Ocean. These locations are along a path taken initially by the main tracer plume. The results of numerically integrating the area under these curves to obtain the ultimate concentrations resulting from continuous injection at the rate used in this study are shown in figure $17 \mathrm{~B}$. The ultimate concentrations for other locations in the estuary were obtained by determining the areas under the time-concentration curves plotted for those locations.

The data presented in figures 9-17 are based on the injection of 750 pounds of tracer during a 24.8-hour tidal day. The ultimate concentrations computed by the method just described were adjusted, for ease of use, to reflect the response to continuous injection of a solute at the rate of 1,000 pounds per 24.0 -hour day. These data were plotted on a base map, and the ultimate isoconcentration map for a nonconservative solute was constructed; this map is shown in figure 18. If a solute is injected continuously into the Colleton River in the vicinity of Victoria Bluff, the resulting distribution and buildup in concentration is described both qualitatively and quantitatively by figure 18. In effect, a buildup to the concentrations shown must be reached before dispersion flushes a solute out of the estuary at the same rate it is injected into the Colleton River. Figure 17 indicates that about 50 days is required for this equilibrium flushing condition to be reached. 


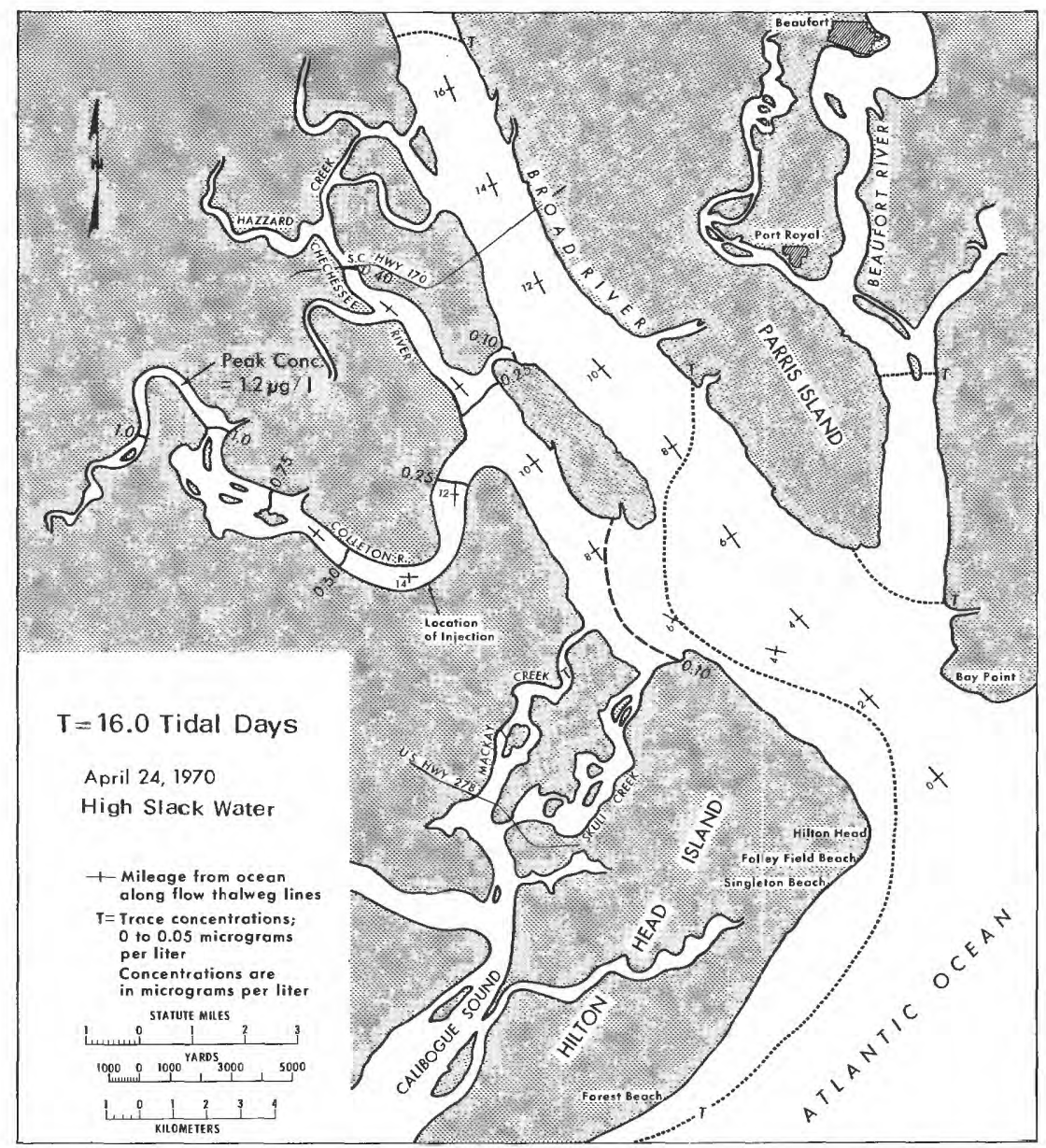

FIGURE 16.--Isoconcentration map of tracer cloud at high slack tide; shift of dye cloud between low and bigh tide can be determined by comparing with figure 14.

The shapes of the curves of figure $17 \mathrm{~A}$ are momentarily affected at certain times and places by unusual tidal or wind conditions, but the area under any particular one, representing the ultimate concentration, is not significantly altered. Because the tide and weather conditions shown in figure 7 were varied but typical of the area during the test, the results of this study should be widely applicable.

\section{DISGUSSION AND CONGLUSIONS}

Figure 18 shows that maximum concentrations are found near the injection point, as might be expected, and that relatively high values exist upstream in the Colleton River. The Broad and Beaufort Rivers 


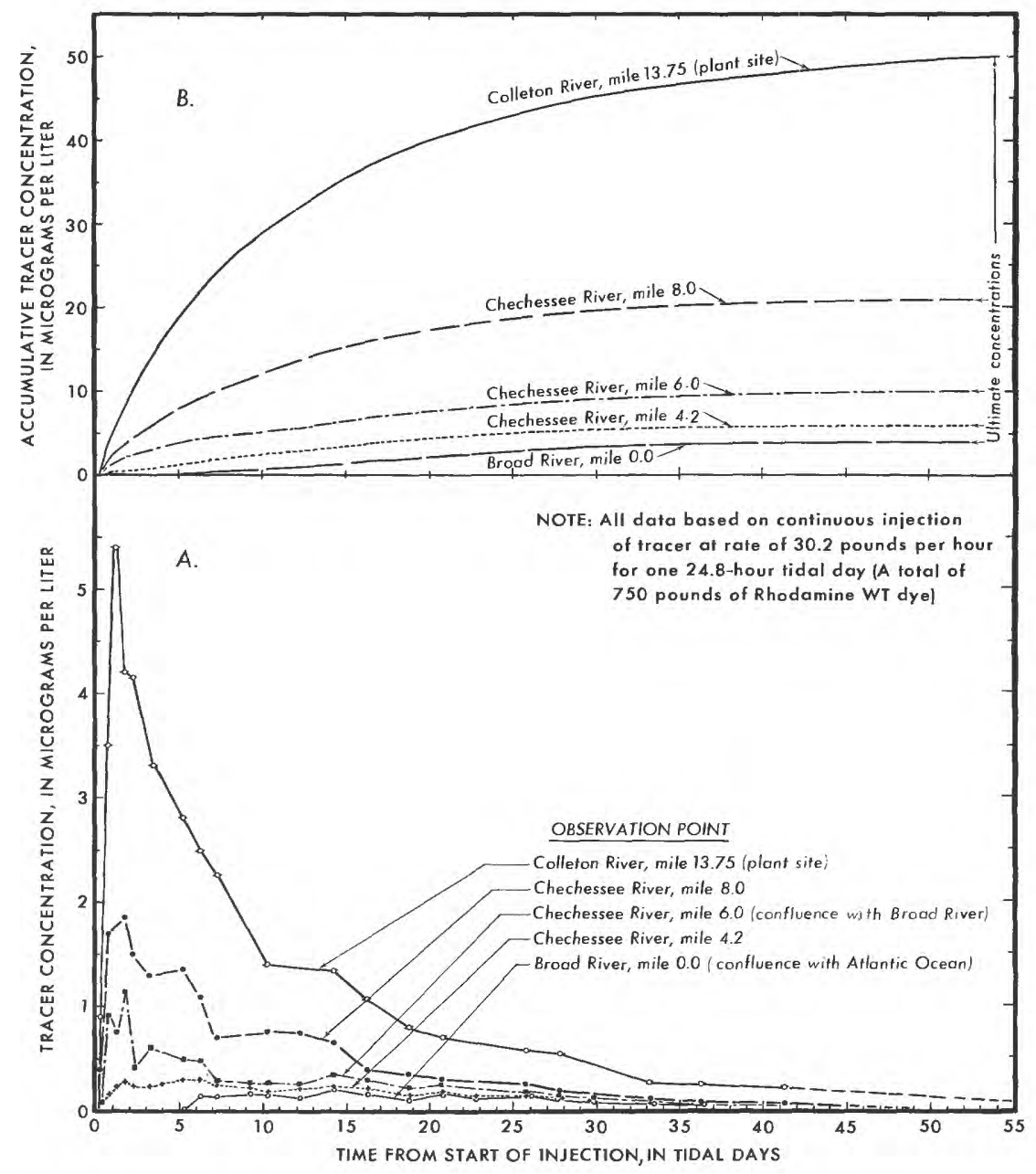

FIgURE 17.-Graphs of concentration curves for selected locations along main tracer plume. $A$, Timeconcentration curves. $B$, Computed ultimate concentration curves.

would experience low concentrations because of their tremendous dilution capacities. Only minor concentrations would be expected along the beaches of Hilton Head Island. It appears that the bulk of the solute would be transported directly seaward along the dominant path of tidal flow in the deep main channel. Because a solute originating in the Colleton River would favor the right bank after entering the Chechessee River, medium concentration would be found in this region and in the northeastern parts of Skull and Mackay Creeks. Under normal conditions no significant amount of solute would pass 


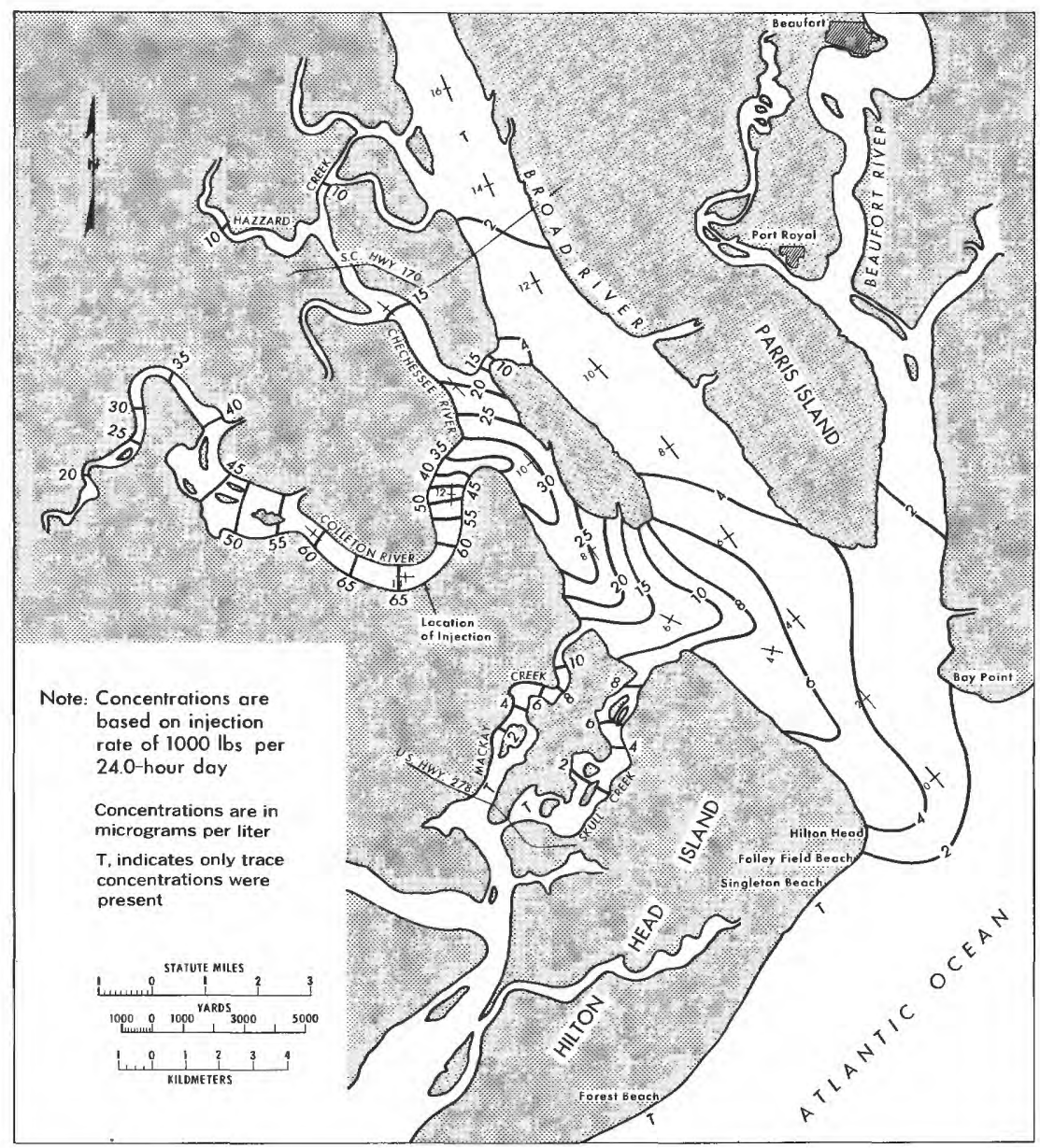

Figure 18.-Map of ultimate concentrations for a nonconservative solute injected continuously at the rate of 1,000 pounds per day.

through Skull and Mackay Creeks into Calibogue Sound. Medium concentration would exist in the upper Chechessee River because of the back flushing of solute from the lower Chechessee River at flood tides.

\section{APPLICATION OF RESULTS}

Figure 18 provides a means of evaluating the concentrations that may be expected at any point in Port Royal Sound from the continuous injection of any amount of solute into the lower reach of the Colleton River. For example, what concentrations would exist in Port Royal Sound from injecting continuously into the Colleton River at Victoria Bluff, 6 million gallons a day of a solute having a 
specific gravity of $1.3^{1}$ and containing 20 percent substance $Y$ ? The actual solute $Y$ is assumed to have the same nonconservative characteristics as the tracer used in the study. Table 1 shows the computation and resulting concentrations at certain selected locations.

\section{TABLE 1.-Computation of ultimate concentrations for selected locations in Port Royal Sound}

[The computed concentration at any given site is found by multiplying the ultimate concentration (from fig. 18) times the injection rate $(6 \mathrm{mgd})$ times the specific gravity of the injected solute (1.3) times the concentration of the injected solute $(0.20)$ times a conversion factor $(8,345)$. For example, at Hilton Head:

$$
4 \times 6 \times 1.3 \times 0.20 \times 8,345=52,000 \mu \mathrm{g} / 1
$$

The conversion factor is used to convert from millions of gallons per day to thousands of pounds of water per dayl

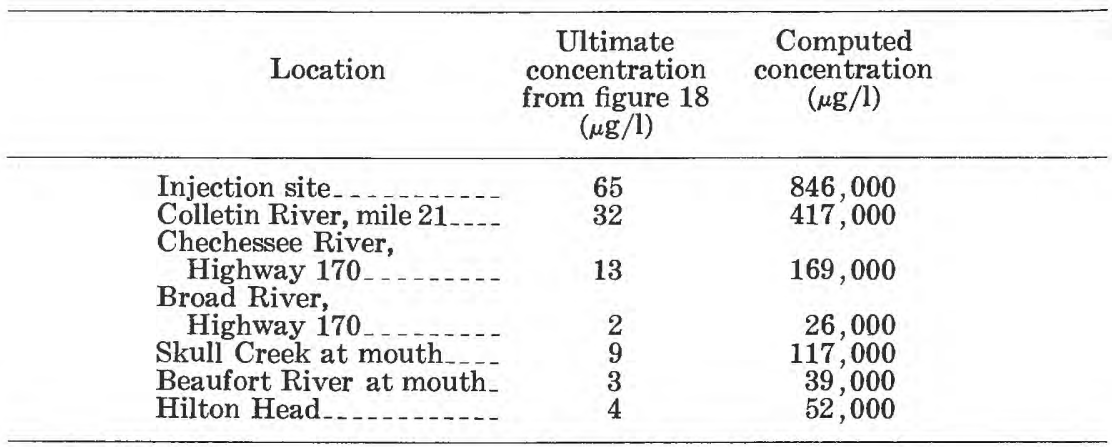

The maximum concentration of $846,000 \mu \mathrm{g} / \mathrm{l}$ occurs in the Colleton River just upstream of the injection site; this value is equivalent to approximately 846 parts per million.

\section{CONSERVATIVE CONCENTRATIONS}

All data thus far presented in this report are observed except for the estimated discharge hydrographs in figures 5 and 7. Bailey, McCullough, and Gunnerson (1966), Dyar (written commun., 1968) and Hetling and O'Connell (1966) have found that Rhodamine WT dye, the tracer used in this test, has a dye loss rate varying from 3.4 to 4.8 percent per day. No attempt was made to compute the dye loss rate by mass computations, for flushing occurred too early in the test to allow reliable evaluation. The dye lot supplied by the manufacturer was tested prior to acceptance and found to be above average. If it is assumed that a rate of 3.0 percent per day would apply, the

\footnotetext{
If the substance is readily soluble, a specific gravity this high will not alter the dispersive characteristics, for mixing takes place under turbulent conditions.
} 
concentrations presented in figure 18 should be multiplied by a factor of 1.8 to represent a conservative solute. Proper evaluatior of the ultimate concentrations thus requires not only a knowledge of the amount being injected, but also information on the chemical, biochemical, and physical reactions that affect the decay rate. Certain substances, such as chlorides, sulfates, sodium, and potassium, are relatively conservative, while others, such as cyanides, phenols, nitrates, and phosphates, are nonconservative (McKee and Wolf, 1963). Most solutes, even those called conservative, generally are less conservative than the tracer used in this test; figure 18 will, therefore, yield safe values, higher than would actually be the case.

\section{EFFECT OF INJECTION AT OTHER LOCATIONS}

The main advantage of a tracer simulation test is that the tracer imitates exactly the movement of a solute injected at a given location. The tracer responds to the hydraulics of the tidal system witrout the necessity of mak ng extensive hydraulic measurements. Utilizing the knowledge of the dispersion characteristics of an estuary obtained in a tracer study in conjunction with some simple mathematical model, it is possible to estimate the effect of an injection at other lo?ations. Such computations would be estimates only in lieu of actual test data. Nevertheless such estimates would be useful for planning purposes.

\section{REFERENCES}

Bailey, T. E., McCullough, C. A., and Gunnerson, C. G., 1966, Mixing and dispersion studies in San Francisco Bay: Journal of Sanitary Engineering Division, Am. Soc. Civil Engineers Proc., v. 92, no. SA5, p. 23-45.

Hetling, L. J., and O'Connell, R. L., 1966, A study of tidal dispersion in the Potomac River: Water Resources Research, v. 2, no. 4, p. 825-841.

Hubbard, E. F. and Stamper, W. G., 1972, Movement and dispersion cf soluble pollutants in the Northeast Cape Fear Estuary, North Carolina: U.S. Geol. Survey Water-Supply Paper 1873-E (in press).

Levenspiel, Octave, 1962, Chemical reaction engineering, an introduction to the design of chemical reactors: New York, John Wiley \& Sons, 501 p.

Linsley, R. K., Kohler, M. A., and Paulhus, J. L., 1958, Hydrology for engineers: New York, McGraw-Hill Book Co., p. 200-202.

McKee, J. E., and Wolf, H. W., 1963, Water quality criteria, Pub. no. ₹-A: The Resources Agency of California State Water Quality Control Board, p. 10-27.

Webster, D. S., Proctor, J. F., and Marine, I. W., 1970, Two-well tracer test in fractured crystalline rock: U.S. Geol. Survey Water-Supply Paper 1544-I, 122 p.

Wilson, J. F., Jr., 1968, Fluorometric procedures for dye tracing: U.S. Geol. Survey Techniques of Water-Resources Inv., book 3, chap. A12, $31 \mathrm{p}$.

Yotsukura, Nobuhiro, 1968, Discussion of longitudinal mixing in natural streams: Journal of Sanitary Engineering Division, Am. Soc. Civil Engineers., v. 94, no. SA3, p. 568-571. 